Kansas State University Libraries

New Prairie Press

\title{
A STATISTICAL ANALYSIS OF THE PERFORMANCE OF MILKING SYSTEM VACUUM REGULATORS
}

\author{
Linda J. Young \\ Gerald R. Bodman \\ Eugene C. Boilesen \\ Walter W. Stroup
}

See next page for additional authors

Follow this and additional works at: https://newprairiepress.org/agstatconference

Part of the Agriculture Commons, and the Applied Statistics Commons

\section{(c) $(1) \Theta \Theta$}

This work is licensed under a Creative Commons Attribution-Noncommercial-No Derivative Works 4.0 License.

\section{Recommended Citation}

Young, Linda J.; Bodman, Gerald R.; Boilesen, Eugene C.; and Stroup, Walter W. (1991). "A STATISTICAL ANALYSIS OF THE PERFORMANCE OF MILKING SYSTEM VACUUM REGULATORS," Conference on Applied Statistics in Agriculture. https://doi.org/10.4148/2475-7772.1419

This is brought to you for free and open access by the Conferences at New Prairie Press. It has been accepted for inclusion in Conference on Applied Statistics in Agriculture by an authorized administrator of New Prairie Press. For more information, please contact cads@k-state.edu. 


\section{Author Information}

Linda J. Young, Gerald R. Bodman, Eugene C. Boilesen, and Walter W. Stroup 


\title{
A STATISTICAI ANAIYSIS OF THE PERFORMANCE OF MILRING SYSTEM VACUUM REGULATORS
}

\author{
Iinda J. Young', Gerald R. Bodman², Eugene C. Boilesen', Walter W. Stroup' \\ Departments of Biometry and Biological Systems Engineering ${ }^{2}$ \\ University of Nebraska, Iincoln, NE
}

\begin{abstract}
Milking machine vacuum regulators were tested at dairies across the United States over a period of twelve years. The drop in vacuum level with increasing air flow for each regulator tested was modeled using segmented regression. Three measures of regulator performance were considered: the slope of the line in the first phase, the variability about the first line, and the join point (after which vacuum pressure began to drop rapidly). The distribution of the join point was estimated based on an accelerated failure time model with censoring, Weibull errors, a model effect, and a linear effect of set point vacuum. For each model, the average slope of the first line, the average variability about the line of the first regime, and the estimated median cfm (cubic feet of air per minute, New zealand standard) for a join point with set point vacuum of $13 \mathrm{in.} \mathrm{Hg} \mathrm{were} \mathrm{standardized.} \mathrm{These} \mathrm{standardized} \mathrm{values} \mathrm{were} \mathrm{used} \mathrm{in} \mathrm{a}$ cluster analysis to identify four performance groups of regulator models.
\end{abstract}

\section{INTRODUCTION}

The dairy industry focuses on producing high-quality milk at the lowest possible cost. Milking machines are used extensively to extract milk from the cows. In preparation for the milking process, the cow's teats are "cleaned" with a sanitizing solution and dried, usually with single-service paper towels. In most instances, sanitizing of the teats and udder is followed by extraction of several squirts of milk (foremilk) to allow visual examination for evidence of clinical signs of abnormal milk. Handling of the teats and massaging of the udder during this premilking activity stimulates the cow and triggers the pituitary gland to release oxytocin. The oxytocin, better known as the "let-down" hormone, causes muscle-like tissue surrounding the alveoli where the milk is produced within the udder to contract. This contraction ejects or squeezes milk out of the alveoli into the duct and cistern system of the udder through which the milk flows to the teat for subsequent removal by the milking machine or by hand.

The contraction of the alveoli causes the pressure to increase rapidly (Figure 1). This increased pressure enhances the milking process by causing a greater pressure differential between the udder and milking system. As illustrated in Figure 1, the influence of the oxytocin remains at a high level for approximately five minutes. Over the next period of about five minutes, the oxytocin concentration and associated pressure within the udder diminish to pre-milking levels.

For maximum milk yield and most efficient harvesting of the milk crop, the bulk of the milk must be removed from the cow during this most productive time. The milking machine vacuum regulator has the responsibility of maintaining a constant vacuum pressure so that this can be accomplished. The goal is to achieve maximum milk yield in the shortest feasible time with minimum insult to the teats and udder. Any activity which causes irritation or trauma to the teats or udder increases the risk of mastitis.

Mastitis, by definition, is an inflammation of the teats or udder. Mastitis degrades milk quality and because of decreased mammary system function causes milk yield or production to be reduced. The cost of mastitis is estimated to be $\$ 200$ per cow per year or $\$ 2$ billion annually to the dairy industry. Failure to keep a constant pressure during the 
milking process can cause or aggravate mastitis. Although an infection is not necessary to cause a cow to suffer from mastitis (inflammation of the udder), most (over 958) cases of mastitis do involve some infectious agent (bacteria, yeast, mold, etc.). These foreign pathogenic (disease-causing) agents enter the udder through the teat canal -- the same opening through which milk is removed from the udder. (An exception to this route of entry would be injuries which directly penetrate the udder.) Variations in vacuum level within the milking system can cause reverse pressure gradients to develop across the teat opening, i.e., the pressure in the milking system is greater than the pressure in the teat (Galton, et al., 1988). This reverse pressure gradient is one mechanism by which pathogenic organisms can be mechanically forced up into the teat -- and subsequently the udder -- thereby increasing the risk of a new infection becoming established.

Erratic vacuum levels in the milking system increase trauma to the teats. A vacuum regulator functions as an air inlet valve to cause the vacuum pump to operate at the same point along its performance curve. Maintaining a constant airflow rate into the milking system results in the same vacuum level within the basic milking system. The air inlet opening within the vacuum regulator must constantly adjust during milking to maintain a constant airflow rate through the milking system as the operation of other system components change, e.g., the number of units actually attached to cows at a given moment, in order to maintain a constant vacuum level. The initial, non-milking vacuum level of the milking system is determined by the system's line height (low = $12-13$ ", mid-height $=12-14 "$, high $=13-15^{\prime \prime}$ ) and how the installer/dealer or producer adjusts the vacuum regulator. The "set point" refers to the vacuum level when the airflow meter is closed, i.e., all air is entering the milking system via the regulator (less what enters through leaks in the system).

Numerous vacuum regulator models are available to producers. These models vary in their ability to maintain a constant vacuum airflow rate. In addition, vacuum regulators of the same model vary in their performance. A study was undertaken to evaluate the performance of milking machine regulators in service at dairies for the purpose of identifying models that consistently perform better than others.

Milking machine vacuum regulators were tested as installed at dairies across the United States over a period of twelve years. For each regulator, the set point vacuum level, in. Hg, was recorded. Then the air flow, measured in cfm (NZ) using a calibrated airflow meter, was increased in increments. The vacuum level, as measured by a direct-reading mercury manometer, was recorded after each increase in air flow. This was continued, about half the time, until an accelerated drop in vacuum was observed for each increment in cfm. The remainder of the regulators maintained fairly constant vacuum during the testing period, and the accelerated drop in vacuum with increasing $\mathrm{cfm}$ was not observed. The number of observations made of any given vacuum regulator ranged from 3 to 24. Since the model was the choice of the producer and not under the control of this study, varying numbers of regulators of each model were tested. Thirteen models had enough (see Table 1) regulators evaluated to be included in the study: Bou-Matic Bouvac; Bou-Matic Weighted Lever; Conde; Delaval Dead Weight, Weighted Sleeve; Delaval VRS/VRM; Sentinel 100; Sentinel 350; Sentinel Mark-1; Surge Equalizer I; Surge Equalizer II; Surge Iiquid Cushion; Universal Weighted Lever; and Westfalia Vacurex. Measures of vacuum regulator models performance and identification of performance groups were desired.

\section{MODELING INDIVIDUAL REGULATORS}

Plots depicting the drop in vacuum pressure as the cfm increases provide insight into the data. A characteristic pattern is shown in 
Figure 2. The regulator holds vacuum fairly stable until a critical point at which the pressure begins to drop rapidly. Other regulators, such as the one in Figure 3 , continued to maintain stable vacuum throughout testing. While most of the regulators fell neatly into one of these groups, a few regulators had erratic responses (see Figure 4). Even though the patterns are discernible for individual regulators, these are no longer apparent when all data points for a given regulator model are considered simultaneously as in Figure 5. Due to this and the manner in which the data were collected, initial efforts focused on modeling each of the regulators.

Consider again the data from a regulator that was tested until it failed (Figure 2). ("Failure" could be the result of the characteristics of the individual vacuum regulator or airflow through the flow meter exceeding system capacity.) Two-phase (or segmented) regression appears to be appropriate. The data in the first phase depict a linear relationship between the drop in pressure and the air flow. The second phase of the regression is the region beginning at the point where the regulator begins to allow a rapid loss in vacuum level. While the relationship in drop of pressure and air flow continues to be linear, the slope of the line will be significantly more negative than that of the first-phase.

The regression provides three measures of interest on each regulator. First, the slope of the line in the first phase should be close to zero since this would represent the case in which the regulator allows little or no change in vacuum level before it begins to fail. Second, since mastitis may result not only from drops in pressure but also from fluctuations in the vacuum pressure, the variability about the line in the first phase should be as small as possible, preferably zero. Last of all, the value of the join point between the two phases should be "large". This occurs when the regulator maintains stable vacuum until a high air flow rate results in its failure. To recap, for each regulator, emphasis will be placed on (1) the estimated slope of the line in the first phase, (2) the estimated variability about the first line, and (3) the join point between the two phases.

Therefore, the performance of each regulator was modeled using

$$
\begin{aligned}
y_{1} & =\beta_{01}+\beta_{11} x_{i}+\epsilon_{1 i}, x_{i} \leq \tau \\
& =\beta_{02}+\beta_{12} x_{1}+\epsilon_{2 i}, x_{1}>\tau
\end{aligned}
$$

where $y_{i}$ is the drop in pressure from the initial vacuum level and $x_{i}$ is the air flow. Hudson's (1966) method (see also Schwarz, 1978) was used to estimate the parameters of the model. This method is based on minimizing the residual sum of squares for the fit, but certain criteria on the location of the join point $\tau$ must be satisfied. First, the join point is required to be in the range of the independent variable, the cfm in this case, but far enough from the endpoints so that a unique regression can be fit to each regime. Also, the join point must occur on or between the two data points which are the interior points of the two regimes. The join point is often constrained to satisfy these criteria before a residual sum of squares is calculated. Further the lines are constrained to be continuous at the join point and thus intersect. The resulting regression ines for one of the regulators is depicted in Figure 6.

Now recall that some regulators maintained stable vacuum throughout the testing period. For these, a two-phase regression would not be appropriate. Thus, a test of coincidence is of particular interest. A likelihood ratio test was performed. The test statistic is formed by the ratio of the likelihood that one switch occurred and two lines are needed to describe the data over the likelihood that no switch occurred and the data can be adequately described with a single line (Quandt, 1958, Hudson, 
1966). If the Observed Significance Level associated with this test was less than 0.1, we concluded that a two-phase regression was needed. Otherwise, we used a single line to describe the behavior of the regulator (see Figure 7).

\section{EVALUATION OF REGULATOR MODELS}

Once this work was complete the focus turned to evaluation of the regulator models. Figure 8 provides a view of the largest, smallest, and average estimated slopes associated with the first regime. Note: In the cases for which we used a single line to describe the behavior of the regulator, the slope of this line is included in the analysis and in the computation of variability about the line of the first regime.

The average variability about the line of the first regime was obtained for each regulator model. These averages as well as the ranges of estimated variances for the thirteen models are shown in Figure 9.

Now consider the join point. About half the regulators did not have a significant join point. For these, the cfm at which they began to fail was assumed to be at a level above the last cfm tested, resulting in censored data. The distribution of failure cfm's was modeled using an accelerated failure time model (Lawless, 1982). Since these regulators were tested on-site, a number of factors, other than model, could possibly affect the failure time. The length of time a regulator has been in service, the time since the regulator was last cleaned, and the system capacity are just some factors that could have an impact. of these, the set point vacuum level was considered most critical and could not be ignored. Therefore, we used the following regression model for failuretime data with right censoring based on the Weibull distribution:

$$
\log \left(c_{i}\right)=\beta_{0}+\beta_{1} I_{i}+m_{j}+\sigma \epsilon_{i}
$$

where $c_{i}$ is either $\tau$, the air flow $\mathrm{cfm}$ of the estimated join point, or the censored value for the $\mathrm{cfm}$ level (if no join point was detected), $I_{i}$ is the initial pressure used to test the ith regulator, and $m_{j}$ is the effect of the jth regulator model with the constraint that

$$
\Sigma_{m_{j}}=0
$$

The $\epsilon^{\prime} s$ are assumed to be errors with a standard Weibull survival function. Using the following parameterization of the Weibull,

$$
F(x)=1-e^{-\epsilon x^{r}}
$$

then $\sigma=1 / \gamma$. Further, $\alpha=\exp (-\mu / \sigma)$ where $\mu=\hat{\beta}_{0}+\beta_{1} I_{i}+m_{j}$ depicts the relationship of time of failure and set point vacuum as well as regulator effect.

Estimates of the $0.05,0.1,0.25,0.5,0.75,0.9$, and 0.95 quantiles were obtained for each regulator model and set point vacuum levels of 11 , $12,13,14$, and $15 \mathrm{in.} \mathrm{Hg}$. The air flow, cfm, at which each regulator model began to fail increased as the set point vacuum decreased. A characteristic pattern is shown for the sentinel 350 regulators in Figure 10.

Large sample normal approximations based on the observed information matrix were used to compute standard errors of the parameter estimates. These were then used to set $95 \%$ confidence limits of the estimated quantile values for each regulator model (Lawless, 1982). The estimated distribution function and $95 \%$ confidence limits for three regulator models 
are depicted in Figures 11 to 13 .

The average slope of the first regime line, the variability about that line, and the 0.5 quantile with initial vacuum of $13 \mathrm{in}$. Hg were estimated for each regulator model (see Table 1). These three measures of regulator performance were standardized to a variance of 1 . The standardized measures were used in a cluster analysis with the Euclidean distance between clusters computed using the average-linkage algorithm (Johnson and Wichern, 1988). Four clusters gave the following groupings: (1) The sentinel 350 was superior by all three criterion and can easily be considered the best regulator tested. (2) The Bou-Matic Bouvac, Delaval VRS/VRM, Sentinel 100, Sentinel Mark-I, Surge Equalizer II, and Westfalia Vacurex were in the second best performance group. (3) The third performance group consisted of Bou-Matic Weighted Iever, Conde, Surge Liquid Cushion, Surge Equalizer I, and Universal Weighted Lever. (4) The performance of the Delaval Dead Weight, Weighted sleeve was substantially below that of other regulator models. These groupings may be depicted in three dimensions as in Figures 14 and 15 .

\section{SUMMARY}

Thirteen milking machine vacuum regulator models were tested on-site at dairies across the United States over a period of twelve years. segmented regression was used to model the drop in vacuum level with increasing air flow for each regulator tested. For each regulator, a likelihood ratio test of coincidence was conducted. If a single regression line adequately described the data, then it was assumed that vacuum was maintained at a stable level throughout the testing period and that testing ceased prior to regulator failure. When the regulator maintained stable vacuum under increasing air flow until a point at which vacuum began to drop rapidly with each increment in air flow, segmented regression was needed. The join point of the two regression lines was the estimated failure point. The distribution of the join points was estimated based on an accelerated failure time model with censoring, Weibull errors, a model effect, and a linear effect of set point vacuum. The last air flow, cfm, tested provided the censored value for the regulators that maintained stable vacuum throughout testing. For each regulator model, the average slope and the average variability about the line describing regulator behavior prior to failure and the estimated median failure cfm for a set point vacuum of 13 in. Hg were standardized to a variance of one. Clustering on these three standardized variables resulted in the identification of four performance groupings.

\section{ACRNOWLEDGMENT}

This is Journal Series No. 9724 of the Agricultural Research Division, University of Nebraska.

\section{REFERENCES}

Galton, D.M., D.I. Aneshanaley, L.G. Petersson, C.S. Czarniecki and N.R. scott. 1988. pressure gradients across the teat canal during machine milking. Proceedings of the Milking system and Milking Management Conference, Northeast Regional Agricultural Engineering Service, Ithaca, NY. pp. 114-117.

Hudson, D. 1966. Fitting segmented curves whose join points have to be estimated. Journal of the American Statistical Association, 61: 10971129 .

Johnson, Richard A. and Dean W. Wichern. 1988 . Applied Multivariate Statistical Analysis, 2nd Ed. Englewood Cliffs, New Jersey: Prentice Hall. 
Lawless, Jerald F. 1982. Statistical Models and Methods for Iifetime

Data. New York: John Wiley \& Sons.

Quandt, R. E. 1958. The estimation of the parameters of a linear

regression system obeying two separate regimes. Journal of the American Statistical Association, 53: 873-880.

Schwarz, Marion J. 1978. Estimating the Join Point of Two Regression

Regimes. Thesis for M.S. Degree, The University of Arizona.

Table 1

\begin{tabular}{|c|c|c|c|c|}
\hline $\begin{array}{l}\text { Regulator } \\
\text { Model }\end{array}$ & $\begin{array}{l}\text { Number } \\
\text { Tested }\end{array}$ & $\begin{array}{l}\text { Average } \\
\text { slope of } \\
\text { lst Line }\end{array}$ & $\begin{array}{l}\text { Average } \\
\text { Variability } \\
\text { about Iine } 1\end{array}$ & $\begin{array}{l}\text { Estimated } \\
\text { Median cfm } \\
\text { for Failure* }\end{array}$ \\
\hline Bou-Matic Bouvac & 7 & -0.00433 & 0.00078 & 87.0 \\
\hline $\begin{array}{l}\text { Bou-Matic } \\
\text { Weighted Lever }\end{array}$ & 5 & -0.02855 & 0.00137 & 49.1 \\
\hline Conde & 14 & -0.03927 & 0.00197 & 131.5 \\
\hline $\begin{array}{l}\text { Delaval Dead } \\
\text { Weight, Weighted } \\
\text { sleeve }\end{array}$ & 30 & -0.02791 & 0.01836 & 90.9 \\
\hline DeLaval VRS/VRM & 53 & -0.00329 & 0.00316 & 144.1 \\
\hline Sentinel 100 & 52 & -0.00332 & 0.00167 & 102.3 \\
\hline Sentinel 350 & 45 & -0.00075 & 0.00101 & 207.8 \\
\hline Sentinel Mark-1 & 23 & -0.00469 & 0.00365 & 118.7 \\
\hline $\begin{array}{l}\text { Surge Equalizer } \\
\text { I }\end{array}$ & 10 & -0.02369 & 0.00604 & 81.5 \\
\hline $\begin{array}{l}\text { Surge Equalizer } \\
\text { II }\end{array}$ & 70 & -0.00821 & 0.00304 & 145.6 \\
\hline $\begin{array}{l}\text { Surge Iiquid } \\
\text { Cushion }\end{array}$ & 37 & -0.01858 & 0.00378 & 60.1 \\
\hline $\begin{array}{l}\text { Universal } \\
\text { Weighted Lever }\end{array}$ & 11 & -0.04730 & 0.00183 & 67.1 \\
\hline $\begin{array}{l}\text { Westfalia } \\
\text { Vacurex }\end{array}$ & 26 & $\begin{array}{c}-0.00971 \\
=\end{array}$ & 0.00269 & 98.5 \\
\hline
\end{tabular}

Set point vacuum of 13 in. $\mathrm{Hg}$ 
Figure 1.

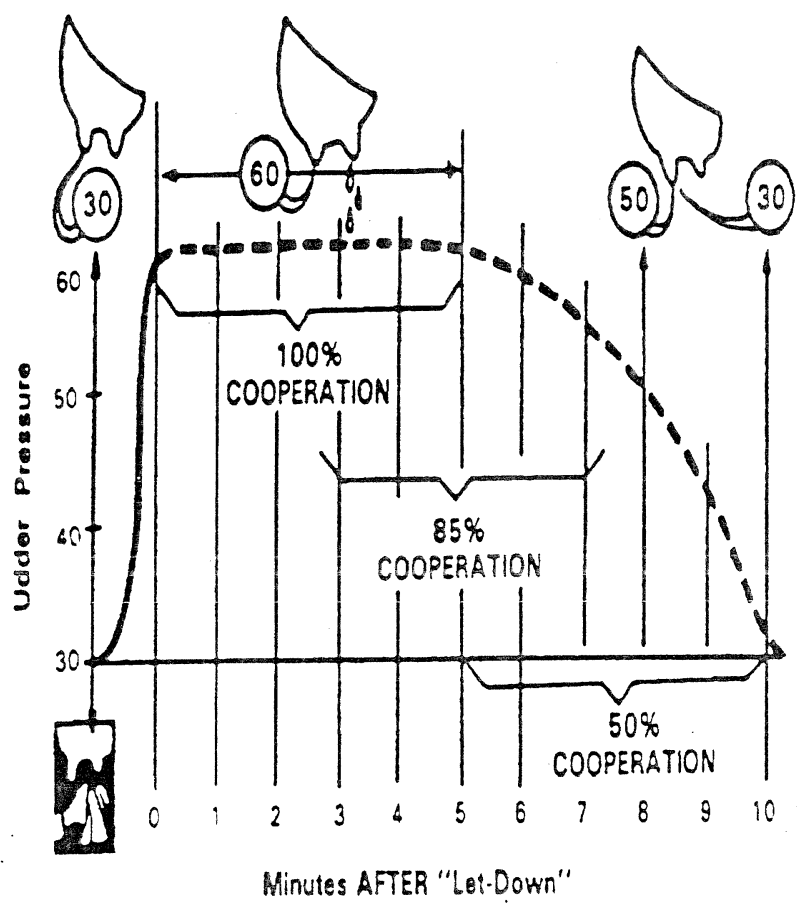

Figure 3. Sentinel-350 Regulators

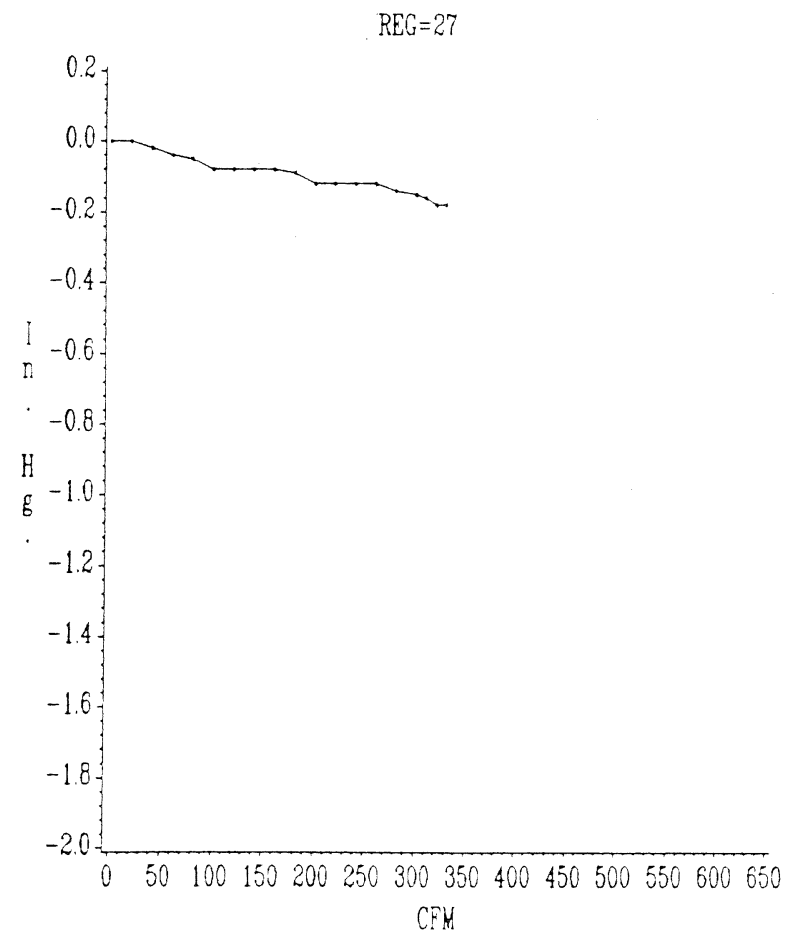

Figure 2. Sentinel-350 Regulators $\mathrm{REG}=17$

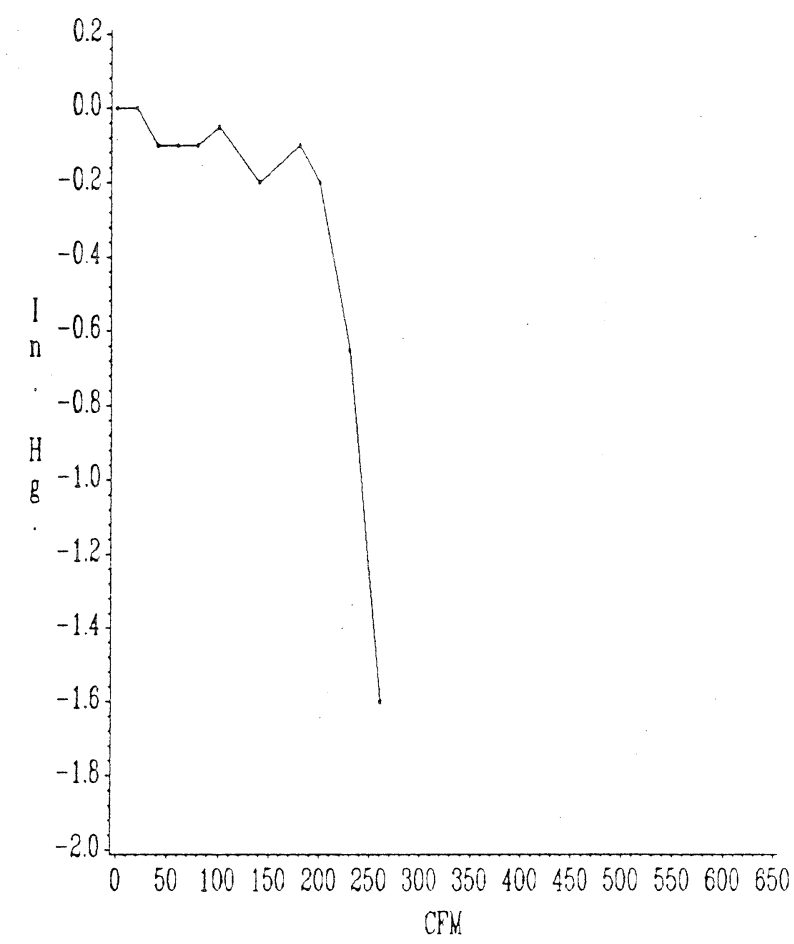

Figure 4. Sentinel-350 Regulators REG $=19$

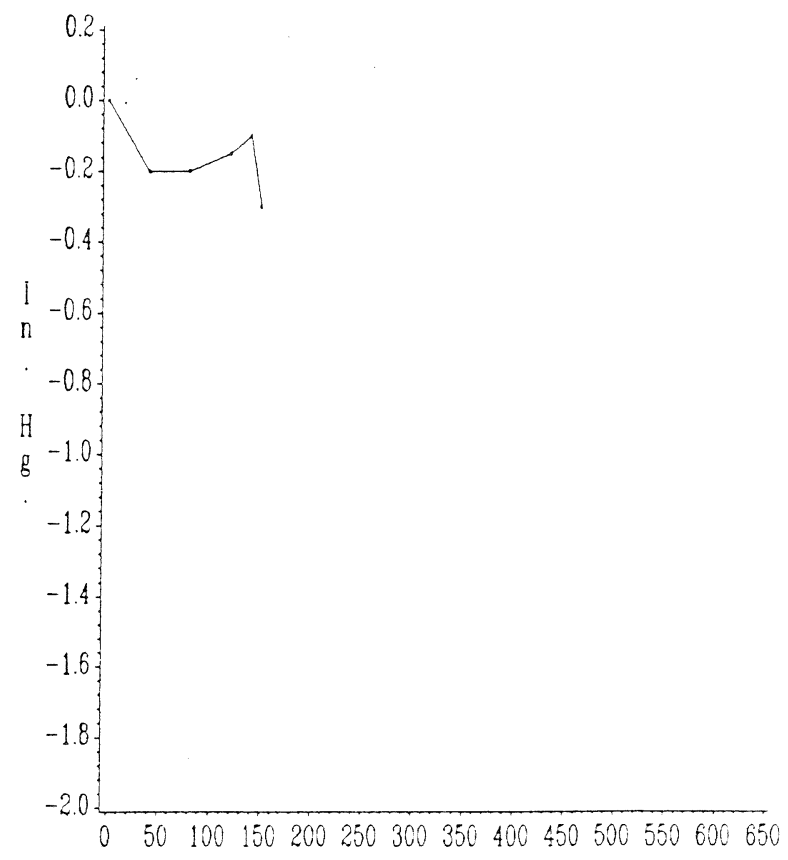
CFN 
Figure 5. Sentinel-350 Regulators

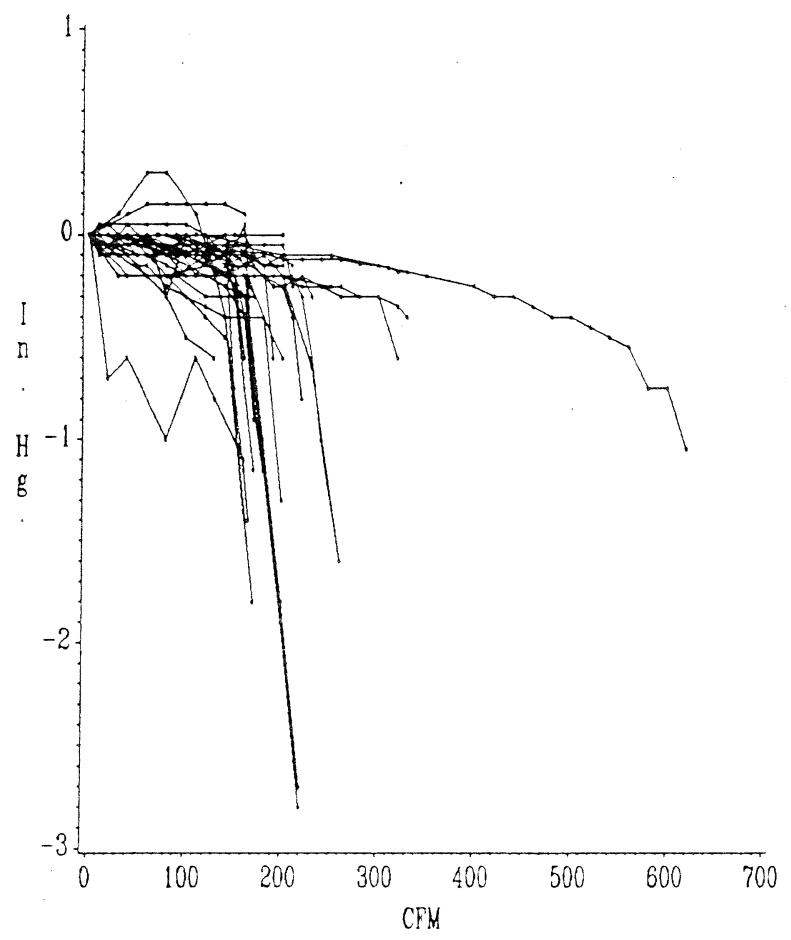

Figure 7. Sentinel-350 Regulators $R E G=27$

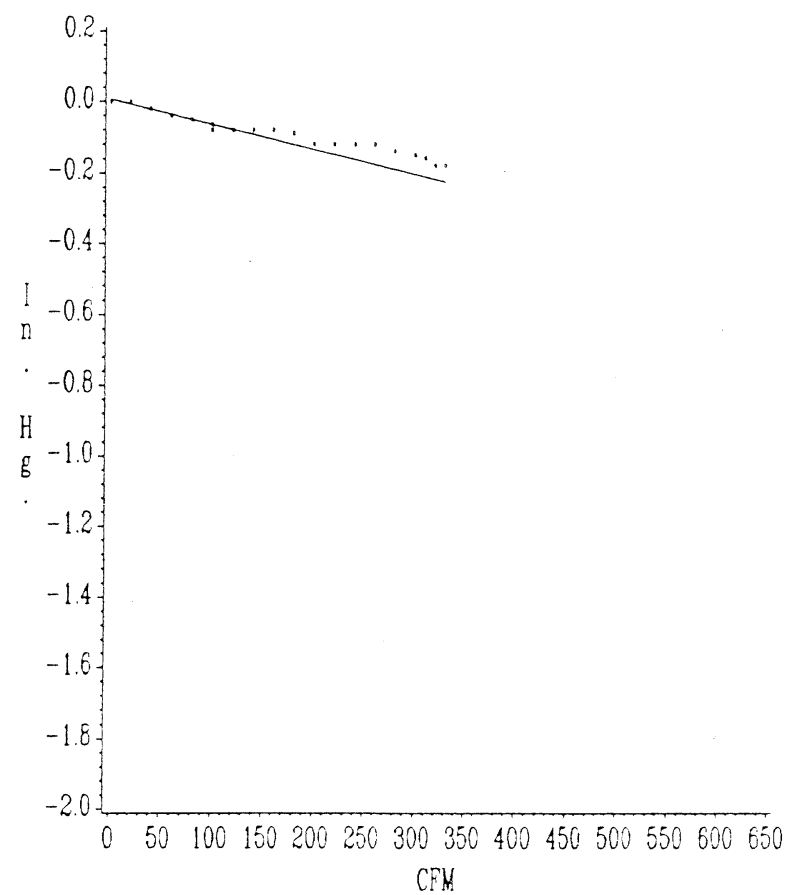

Figure 6. Sentinel-350 Regulators

$\mathrm{REG}=1$ ?

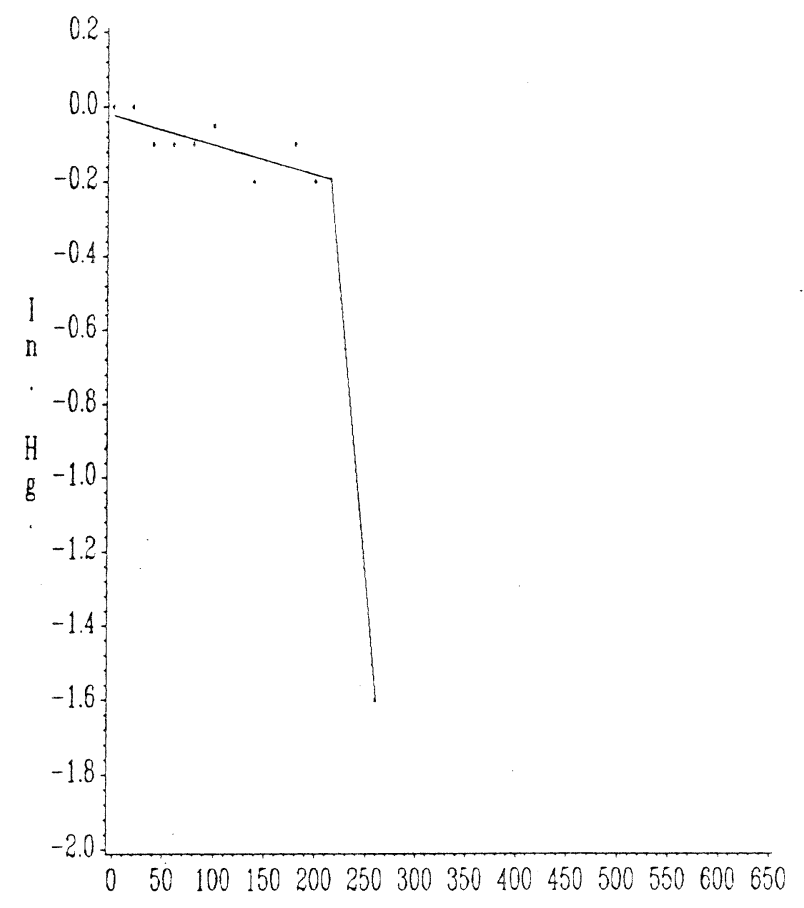

CFH

Figure 8. Estimated Slopes of First Regime

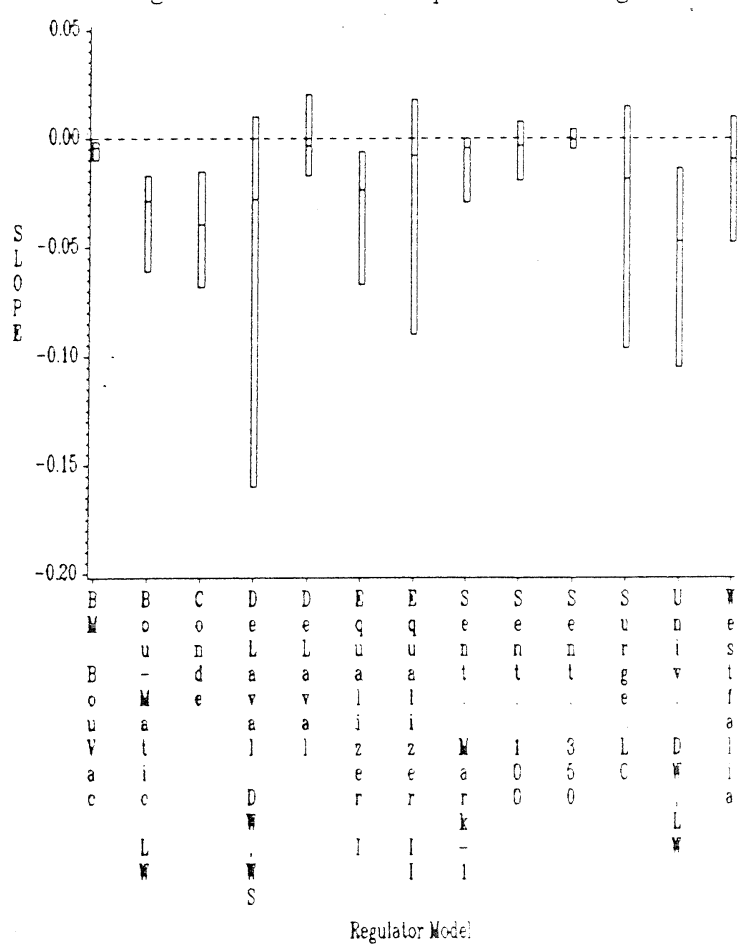


Figure 9. Estimated Varibility About Lines of First Regime

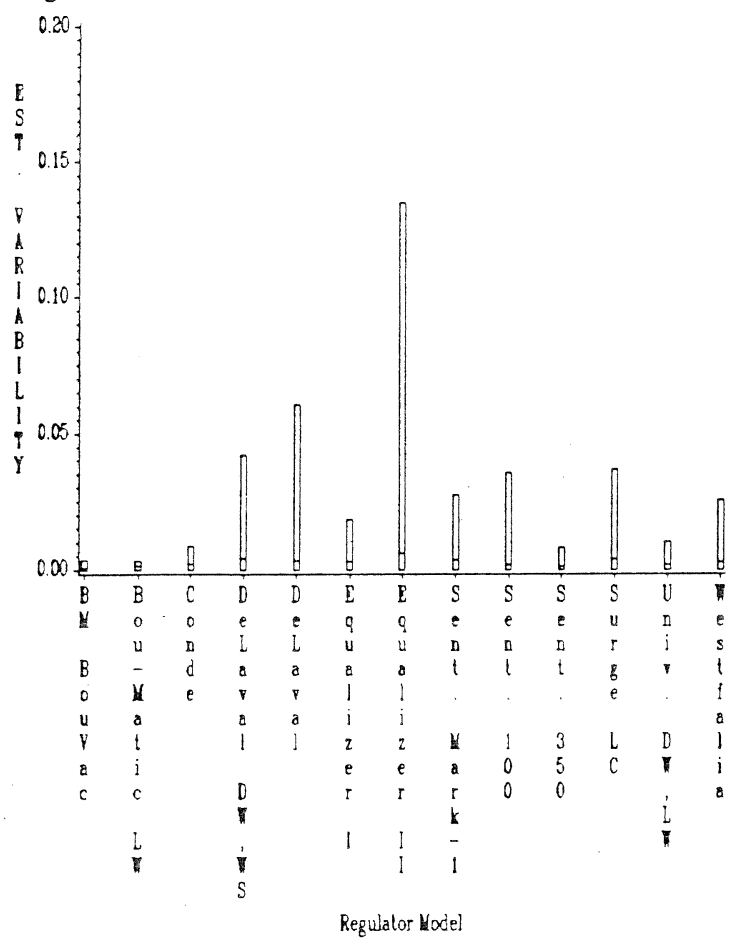

Figure 11. Estimated Quantiles Based on Meibull Regulator Type $=$ Bou-Matic BouVac Set Point $=13$

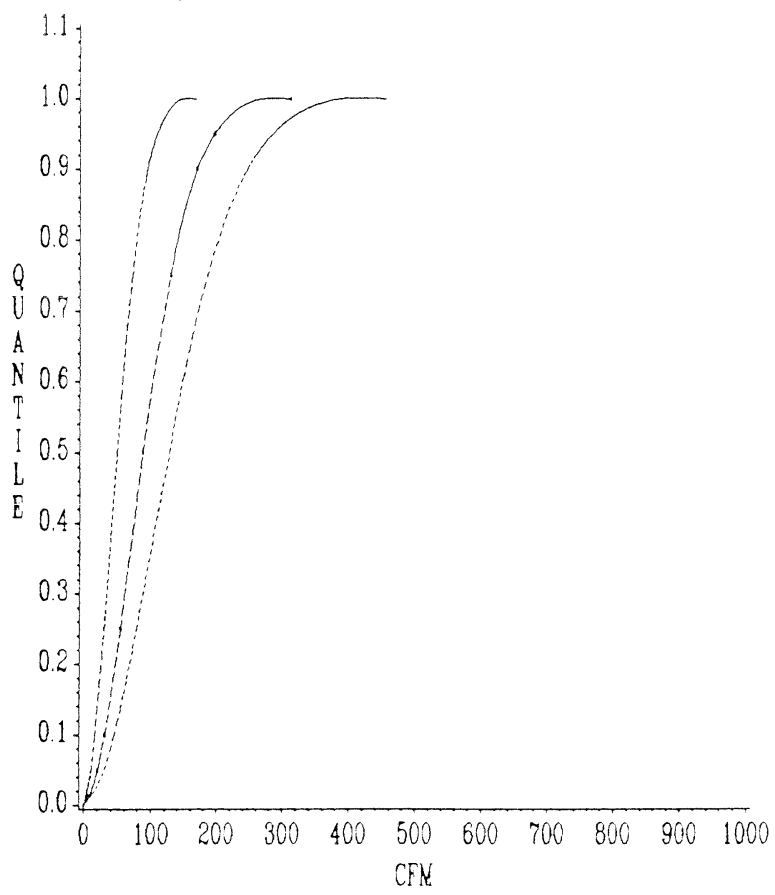

Figure 10. Estimated Distribution Functions for the Sentinal 350 for Differing Set Points

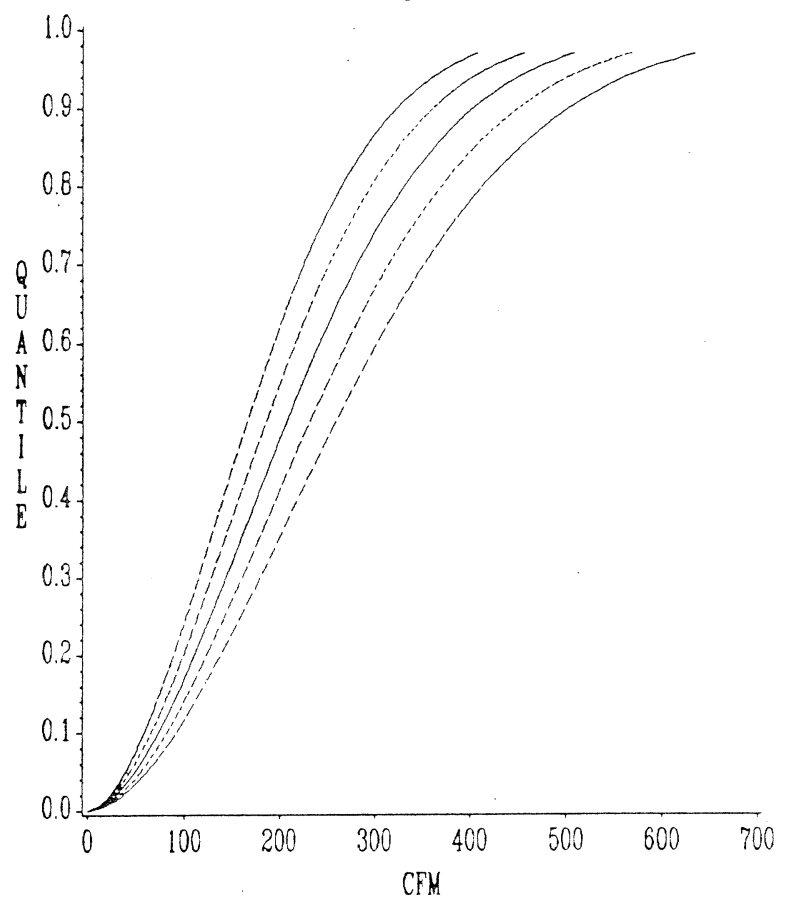

Figure 12. Estimated Quantiles Based on Heibull Regulator Type=Conde Set Point $=13$

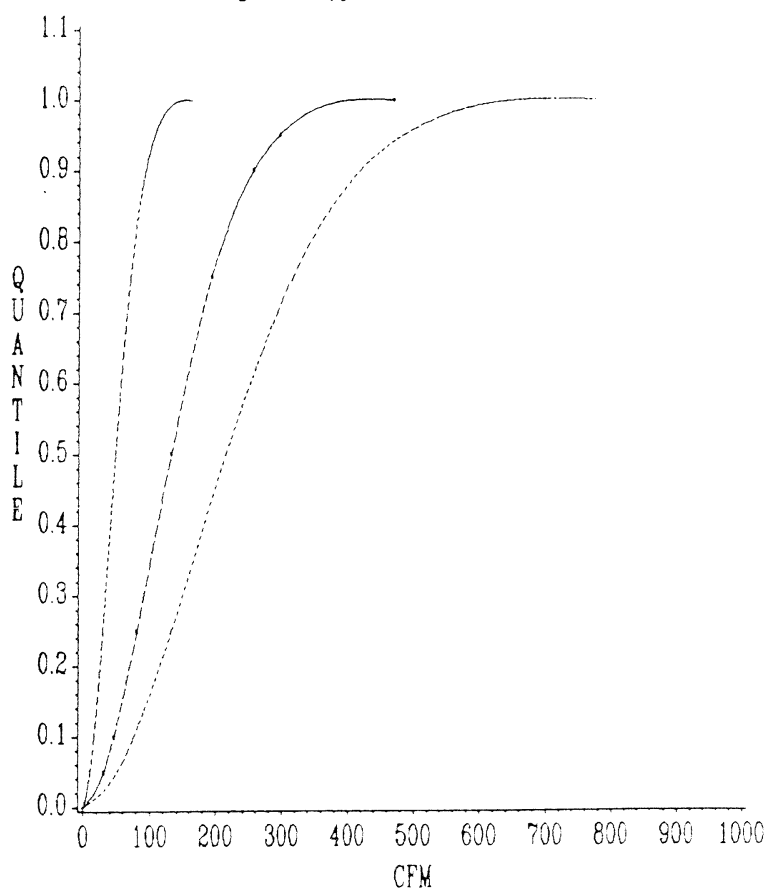


Figure 13. Estimated Quantiles Based on Reibull Regulator Type $=$ Sentinel 350 Set Point $=13$

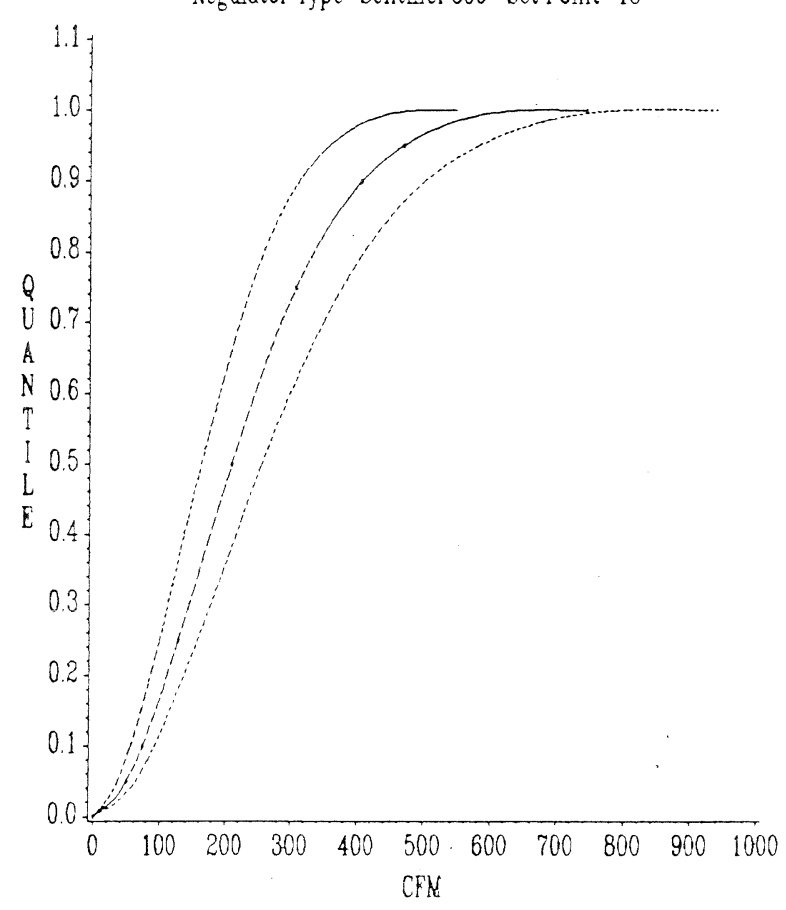

Figure 14. Performance Groupings of Regulators

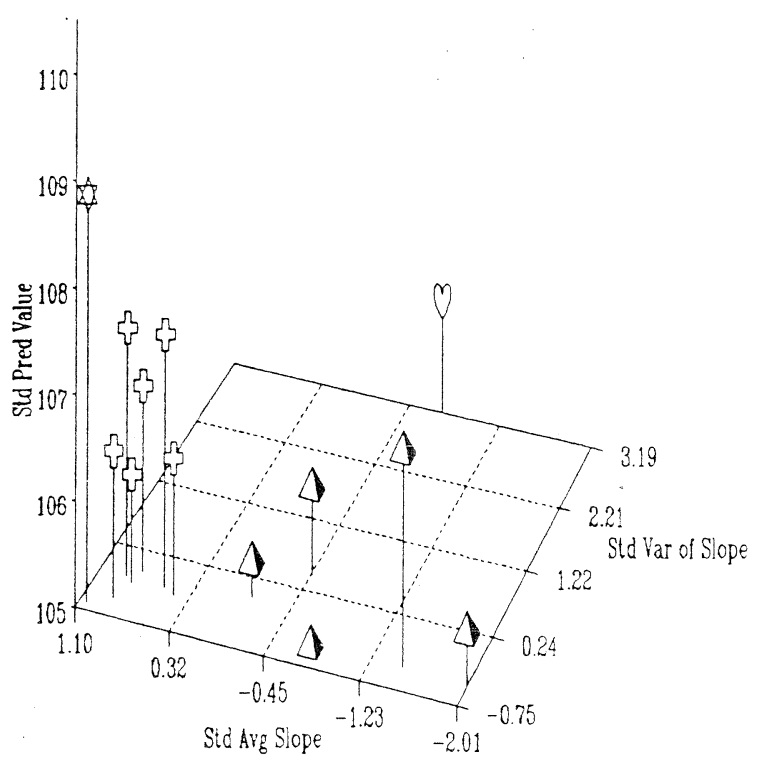

Figure 15. Performance Groupings of Regulators

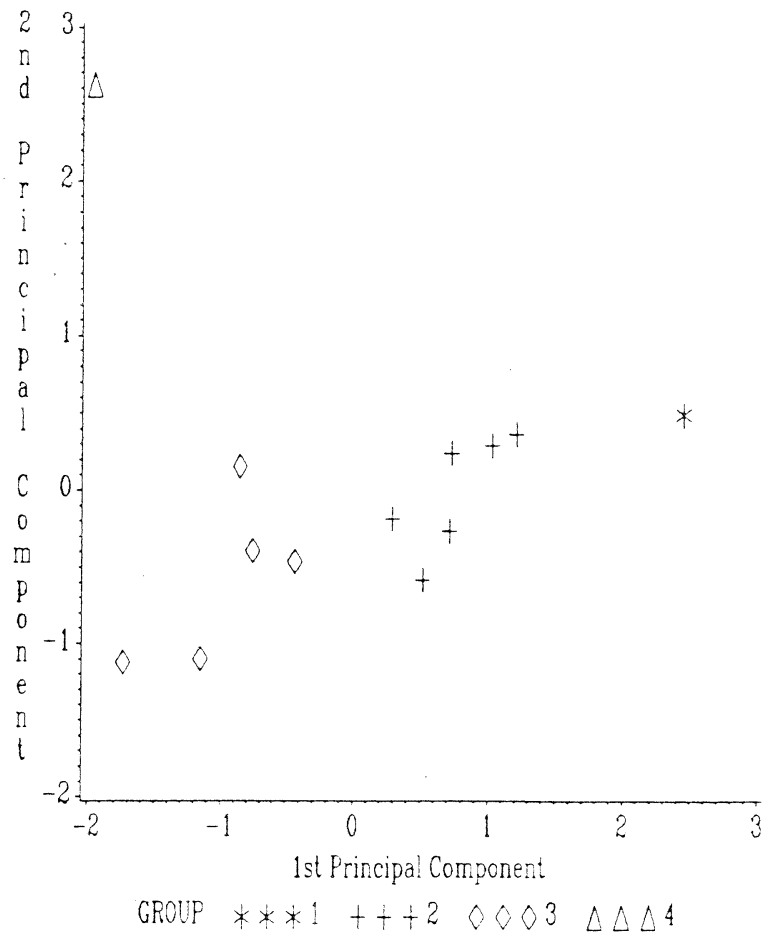

